\title{
Ser de verdad un desplazado: naturalización de la condición de víctima a través de las intervenciones legales post-conflicto en Colombia
}

\author{
Being a Real Displaced Person: Naturalization of \\ the Condition of Victim through Legal Post-Conflict \\ Intervention in Colombia
}

\author{
Gabriel Alberto Ruiz Romero \\ Universidad de Medellín, Colombia \\ Red de Investigadores Jóvenes "Memorias en Red"
}

\section{RESUMEN}

Después de casi quince años de aplicación de políticas de reparación por parte del Estado (además de la intervención continua de algunas ONG y otras instituciones), la población desplazada de Nueva Venecia (Magdalena-Colombia) no ha superado su condición de desplazamiento sino que la ha terminado naturalizando. Esto ha tenido lugar, paradójicamente, en la medida en que ellos han sido el objetivo de diversos instrumentos legales teóricamente diseñados para confrontar dicha condición.

Este artículo analiza cómo estos instrumentos legales han sido desarrollados en tanto "sistemas expertos" (usando el concepto de Anthony Giddens), los cuales han terminado definiendo cuándo una persona es realmente una víctima, no debido a sus experiencias traumáticas pasadas sino a que haya podido pasar exitosamente a través del proceso de registro y permanencia en el sistema mismo. El fortalecimiento de las intervenciones post-conflicto a través de estos sistemas expertos está en el centro de la mutua inmovilidad de las víctimas y las instituciones. Las víctimas, porque desde esa posición obtienen unos mínimos con los cuales mal que bien se las arreglan para sobrevivir; y las instituciones, porque no deben preocuparse en procurar nada más que esos mínimos.

Palabras clave: Procesos de reparación; Ayuda humanitaria; Sistemas expertos; Desplazamiento forzado; Colombia; Conflicto armado.

\section{SUMMARY}

After almost fifteen years of the development of reparation policies carried out by the State (as well as the continuous work of some NGO and other institutions), the displaced population of Nueva Venecia (Magdalena-Colombia) has not overcome but rather naturalized the condition of forced displacement. This has happened, paradoxically, to the extent they have been the target of legal instruments theoretically designed for facing such a condition.

This paper discusses how these legal instruments have been settled as an "expert system" (using the concept of Anthony Giddens), which have come to define when a person is a real victim, not due to his past traumatic experiences but because of successfully going through the process of registration and permanence within the system itself. The strengthening of post-conflict 
interventions through these expert systems, is the heart of a mutual stillness of victims and institutions. For the victims, because from this position they obtain some basic attention with which, for better or worse, they manage to get by; and for the State and institutions, because they do not have to worry about providing anything else but those minimal basics.

Key words: Reparation Processes; Humanitarian Aid; Expert Systems; Forced Displacement; Colombia; Armed Conflict.

Lo esencial es, en todo caso, que cuando los refugiados ya no representan casos individuales, sino, como sucede ahora cada vez con mayor frecuencia, un fenómeno de masas, tanto esas organizaciones como los Estados individuales, a pesar de las solemnes invocaciones a los derechos "sagrados e inalienables" del hombre, se han mostrado absolutamente incapaces no sólo de resolver el problema, sino incluso de afrontarlo de "manera adecuada".

Agamben 2010 [1995]:169

\section{INTRODUCCIÓN}

La noche del 22 de noviembre del año 2000, un grupo aproximado de 60 hombres armados, pertenecientes al Bloque Norte de las Autodefensas Unidas de Colombia $(\mathrm{AUC})^{1}$, realizaron una masacre en el poblado palafítico de Nueva Venecia, pequeño pueblo de pescadores ubicado en mitad de la Ciénaga Grande de Santa Marta, complejo lagunar costero muy cerca del mar Caribe, en el norte de Colombia. Esa noche los paramilitares asesinaron a 38 personas y ocasionaron el desplazamiento masivo de la mayoría de los aproximados 2000 habitantes que tenía entonces el palafito, siguiendo así con la estrategia de tierra arrasada empleada en desarrollo de su expansión armada por todo el país.

En los refugios donde se albergaron momentáneamente o en las ciudades a las que huyeron, los habitantes de Nueva Venecia empezaron a ser registrados como desplazados forzados del conflicto armado. Aunque la mayoría de los que huyeron terminaron por regresar de nuevo al palafito (donde continúan viviendo actualmente), estos individuos siguen siendo considerados por el Estado (y por otras organizaciones) como personas desplazadas, aún pasados casi 15 años después de la masacre. Sigue existiendo para ellos todo un entramado institucional de atención y administración de su condición.

Este artículo examina la forma en que la condición de desplazamiento ha sido interiorizada y asimilada por las personas en la medida en que han sido captadas por dicho entramado. En éste, los desplazados han sido objeto de prolongados mecanismos de intervención, por parte del Estado y de otras organizaciones, que han terminado teniendo un efecto simplificador al contribuir a anclar a los individuos en una

\footnotetext{
${ }^{1}$ Las AUC fue una confederación de grupos paramilitares de ultraderecha, con un comando central nacional encabezado por los hermanos Castaño (Fidel, Carlos y Vicente). Formada a finales de los años 90, desapareció oficialmente como grupo unitario organizado después de una negociación con el gobierno de Álvaro Uribe Vélez en el año 2006.
} 


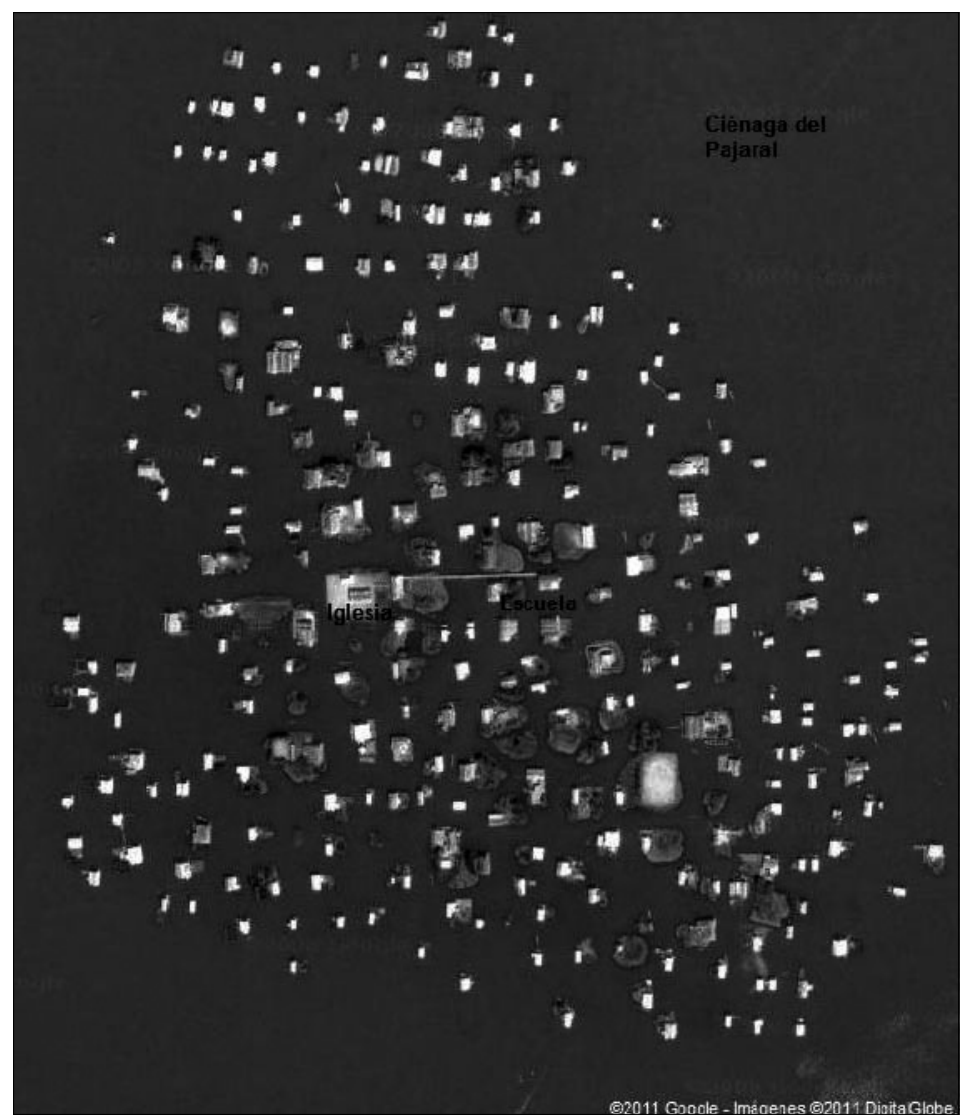

IMAGEN 1.-Vista satelital de Nueva Venecia.

experiencia literal de su victimización. El texto examina cómo esos mecanismos se han desarrollado en clave de sistema expertos (Giddens 2011 [1990]), cuyo funcionamiento escapa a la comprensión de las personas afectadas por ellos. En este sentido, este trabajo se ubica en la misma línea del importante trabajo La sonrisa de la institución. Confianza y riesgo en sistemas expertos (Velasco et al. 2006), pues entiende los mecanismos de reparación como un ejemplo más de esos sistemas especializados de conocimiento abstracto tecno-científico.

El artículo está basado en un extenso trabajo de campo etnográfico realizado entre los años 2011 y 2012. La observación participante en las actividades diarias de la comunidad de Nueva Venecia (Magdalena) constituye la herramienta metodológica fundamental empleada en el desarrollo del trabajo. Durante este periodo, el autor pudo participar en numerosas reuniones y capacitaciones que funcionarios del Estado (u otras organizaciones) llevaron a cabo en el poblado, bien como parte de medidas de reparación, de programas de desarrollo o de ayudas humanitarias que les eran entregadas a los habitantes. Se realizaron adicionalmente más de medio centenar de entrevistas semi-estructuradas, la mayoría a pescadores y habitantes del palafito, pero 
también a funcionarios del Departamento de Protección Social, de la Unidad de Víctimas, de la Oficina de las Naciones Unidas Contra la Droga y el Delito, de la alcaldía municipal de Sitionuevo (municipio al que administrativamente pertenece el poblado de Nueva Venecia) y de la gobernación del departamento del Magdalena. Así mismo, también se entrevistó a miembros de ONG que han desarrollado trabajos en el terreno, al abogado que lleva la demanda de la comunidad de Nueva Venecia contra el Estado colombiano en la Comisión Interamericana de Derechos Humanos, a la fiscal que en el momento investigaba la masacre y a académicos del Centro Nacional de Memoria Histórica que han realizado trabajos extensos sobre las dinámicas del conflicto armado colombiano ${ }^{2}$.

\section{EL DESPLAZADO: DE SUJETO A OBJETO}

El desplazado, como figura dentro de la normativa jurídica, es relativamente nuevo en Colombia. Aunque desplazados forzados han existido en el país desde su propio nacimiento como República, a partir de las guerras civiles que siguieron al proceso de independencia en el siglo XIX y especialmente durante el periodo de violencia bipartidista de mitad del siglo XX (conocido genéricamente como La Violencia, con mayúscula), no es sino hasta la última década del siglo pasado cuando el desplazado se constituye en objeto de una política pública particular y por tanto empieza a existir en términos normativos.

En 1997, a través del decreto 976 y de la ley 387 "por la cual se adoptan medidas para la prevención del desplazamiento forzado; la atención, protección, consolidación y estabilización socioeconómica de los desplazados internos por la violencia en la República de Colombia", el "desplazado interno" nació como nuevo sujeto/objeto de atención para el Estado. En lo que refiere a la atención, la ley se refiere a una "atención humanitaria de emergencia", que en principio estaba determinada para tres meses (prorrogables otros tres), pero que una revisión de la Corte Constitucional ordenó que fuera prorrogable de forma indefinida. Respecto a la "consolidación y estabilización socioeconómica", la ley hace referencia a la obligación del Estado de adelantar acciones a mediano y largo plazo para contribuir a la "sostenibilidad económica y social" de esta población. Tales acciones tienen que ver con el desarrollo de proyectos productivos, fomentos micro-empresariales, capacitaciones técnicas y atención en salud, educación y vivienda.

\footnotetext{
${ }^{2}$ Es importante aclarar que durante el periodo del trabajo de campo, la política de atención a la población desplazada estaba regida por la ley 387 de 1997, la ley 975 de 2005 (conocida como Ley de Justicia y Paz) y el decreto 1290 de 2008 (que estableció reparaciones vía administrativa para las víctimas de la violencia armada). En el año 2011 el Congreso colombiano promulgó la ley 1448 (conocida como Ley de Víctimas y Restitución de Tierras), a través de la cual se establecieron nuevos instrumentos legales para la reparación de las víctimas del conflicto armado. Aunque el trabajo de campo base de este artículo es previo al despliegue institucional de la nueva ley, posteriores visitas del autor al área han permitido observar que la situación descrita en este artículo no ha cambiado sustancialmente. Una primera versión de este texto fue incluida como un capítulo de la tesis doctoral del autor y una versión ampliada está siendo reescrita como parte de un libro que el mismo autor prepara actualmente.
} 
Pero lo más relevante para el objetivo de este trabajo es señalar que esa atención, protección, consolidación y estabilización socioeconómica estuvo en principio a cargo del Sistema Nacional de Atención y Prevención de Desastres, la misma entidad estatal encargada de atender las emergencia producidas por desastres naturales. La condición de desplazamiento quedaba así asimilada — desde su naciente concepción legal- a la de cualquier victimización por un desastre o calamidad natural. El desplazado forzado, víctima del conflicto armado, debía entonces ser atendido por la institución que atendía a las víctimas de inundaciones, terremotos, erupciones volcánicas, etc. Asumir (aunque fuere de forma tácita) que el desplazamiento forzado era un desastre más, equivale a asumir que es, por una parte, intempestivo, y por la otra, producto de condiciones que están por fuera del control (de la responsabilidad) de las instancias políticas del Estado.

Esta consideración inicial del desplazamiento hizo invisible, desde el principio, su dimensión política (Aparicio 2005), transformándolo desde su nacimiento normativo en un problema especialmente de tipo humanitario, que es justamente como se concibe un desastre natural. Bajo estos criterios se hizo perfectamente consecuente que la forma privilegiada de intervención y atención fuese precisamente la de ayuda humanitaria, pensada y desarrollada para atender coyunturalmente situaciones de emergencia que por su propia naturaleza se presentan intempestivamente. Concebido como un suceso imprevisto e inevitable, lo único que puede entonces hacerse es tratar de menguar sus efectos.

A Nueva Venecia no ha parado de llegar esta atención humanitaria "de emergencia". Se ha prolongado en el tiempo desde la masacre paramilitar del año 2000 y ha terminado confundiéndose con otras ayudas humanitarias que han llegado debido a inundaciones o a crisis medioambientales (lo cual no puede asombrar pues, ya lo vimos, en el origen todos los desastres son tratados un poco igual). Al principio, justo después de la masacre, esa atención consistió en la construcción de albergues improvisados en las escuelas del pueblo (Sitionuevo) donde muchos huyeron y en la repartición de mercados en esos mismos refugios. Después del retorno voluntario de la población, esas ayudas no han dejado de llegar esporádicamente, generalmente cuando otro desastre tiene lugar: frazadas y colchones cuando ha habido inundaciones, tejas cuando han pasado vendavales. En ocasiones han sido instituciones del gobierno nacional quienes las llevan (los funcionarios del Departamento de Protección Social); en otras ocasiones ha sido la gobernación del Magdalena, la alcaldía municipal, o incluso alguna ONG la que se ha presentado con estas ayudas.

Pero no sólo se ha dado una larga sucesión de estas ayudas humanitarias, algunas incluso a destiempo y sin atender necesidades reales del terreno, sino que inclu-

${ }^{3}$ El caso de ayudas humanitarias fuera de lugar y a destiempo puede reflejarse en el ejemplo de una entrega de frazadas y colchones que tuvo lugar mientras realizaba el trabajo de campo: dichos elementos llegaron como intervención humanitaria para menguar los efectos de una inundación... ique había tenido lugar seis meses atrás! La entrega de esos elementos no resolvía — por supuesto- los factores que ocasionan las inundaciones, pero ni siquiera eran necesarios y muchos de ellos terminaron arrinconados en la que fuera la sede del centro de salud (hoy abandonada). Hubo después unas discusiones en el poblado porque se rumoraba que un candidato al concejo municipal (quien era el que al parecer había gestionado la entrega de esas ayudas humanitarias) se había apropiado de las mismas para repartirlas como parte de su campaña electoral. 
so algunos servicios básicos fundamentales han terminado reducidos a ayudas ${ }^{3}$. El caso paradigmático de esto es el de la salud: en lugar de la construcción de un centro de salud, de vez en cuanto (especialmente en época electoral) llega al pueblo lo que se conoce localmente como una "brigada de salud", que no es más que un médico y una enfermera que en un día revisan a la población en consultas express al final de las cuales recetan lo único que llevan en esas brigadas: Acetaminofén para los dolores, Canestén para las infecciones en la piel y Albendazol para los parásitos.

La atención humanitaria de emergencia, en resumen, ha sido la forma privilegiada de atención que esta población ha recibido. Todo muy alejado de la "demostración de respeto" que según la RAE define al término atención. Pero más allá de esta consideración de tipo lingüística, lo que puede comprobarse es que los mecanismos de intervención que han tenido lugar en la Ciénaga Grande son interpretados en clave de ayuda humanitaria precisamente porque buscan atender coyunturalmente algunos asuntos, mas no transformar estructuralmente la condición de vulnerabilidad social de la población. Esto puede observarse al verificar que la forma más extendida de reparación que ha tenido lugar en la Ciénaga, a la que todos han podido acceder por considerarse el suyo un caso de desplazamiento masivo, ha sido la de las reparaciones vía administrativa ${ }^{4}$. El dinero que reciben las personas a través de este mecanismo no sólo promueve que se le ponga un precio a la experiencia de horror, sino que en lugar de contribuir a confrontar las razones de la victimización (y por tanto dar garantías de no repetición, lo que iría en consonancia con los alcances de la reparación, tal y como ha sido concebida en el desarrollo de la justicia transicional), lo que hace es producir un alivio temporal... ijusto lo que hace la atención humanitaria de emergencia!

Pero volviendo al desplazamiento en tanto suceso intempestivo y hasta cierto punto inevitable, ¿quién desplaza de esta forma tan inesperada a las personas? La propia ley 387 señala como responsables del desplazamiento al "conflicto armado interno; disturbios y tensiones interiores, violencia generalizada, violaciones masivas de los Derechos Humanos, infracciones al Derecho Internacional humanitario u otras circunstancias emanadas de las situaciones anteriores que puedan alterar drásticamente el orden público". Son pues actos de violencia directa, en la clasificación ya clásica de

${ }^{4}$ Las reparaciones vía administrativa fueron creadas por el gobierno nacional a través del decreto 1290 de 2008 (el cual sería luego reemplazado por el decreto 4800 de 2011). A través de ellas las personas podían acceder a una indemnización pagada por el Estado, sin necesidad de esperar la resolución de procesos judiciales. Lo único que debían hacer era probar que eran víctimas reconocidas del conflicto. Para el caso de los desplazamientos considerados masivos, bastaba comprobar que en el momento del suceso se habitaba en el poblado donde se realizó el desplazamiento, sin ser realmente relevante si la persona en particular se había desplazado o no. Este decreto, en su artículo 5, tenía una tabla que establecía el valor que se pagaba por cada tipo de victimización: Homicidio, Desaparición Forzada y Secuestro: Cuarenta (40) salarios mínimos mensuales legales; Lesiones Personales y Psicológicas que Produzcan Incapacidad Permanente: Hasta cuarenta (40) salarios mínimos mensuales legales; Lesiones Personales y Psicológicas que no causen Incapacidad Permanente: Hasta treinta (30) salarios mínimos mensuales legales; Tortura: Treinta (30) salarios mínimos mensuales legales; Delitos contra la Libertad e Integridad Sexual: Treinta (30) salarios mínimos mensuales legales; Reclutamiento Ilegal de Menores: Treinta (30) salarios mínimos mensuales legales; Desplazamiento Forzado: Hasta veintisiete (27) salarios mínimos mensuales legales. 
Galtung (1969), los que en términos normativos producen una situación que legalmente puede ser denominada como desplazamiento forzado. Y es la emergencia ocasionada por el acto concreto de violencia directa (puesto al mismo nivel de los desastres naturales) la que es objeto de atención institucional.

Concebido de esta forma, no es posible entender el desplazamiento forzado como lo que realmente es: como el acto final de un proceso cuyo origen está en las condiciones sociales de vulnerabilidad que posibilitaron que la población se encontrara en una posición de indefensión frente a cualquiera de los actores armados. La violencia que genera el desplazamiento aparece en esta concepción legal, de cierta manera, como un acto ex nibilo, que al igual que los desastres naturales parece venida de ninguna parte. Esto hace imposible aprehender el desplazamiento en su dimensión política.

Los desplazados nacen así normativamente como seres despolitizados y ahistóricos: despolitizados porque su victimización se iguala a la producida por un fenómeno natural; ahistóricos porque se hace invisible todo el proceso que está detrás de las acciones de violencia directa. Dicho proceso, no obstante, fue el que los hizo en primer lugar víctimas, al relegar su existencia a lo que con Agamben (2010 [1995]) podemos llamar una nuda vida: una vida vulnerable no sólo a las dinámicas del conflicto armado, sino (en primer lugar) a las difíciles condiciones determinadas por la alta desigualdad social propia de la sociedad colombiana.

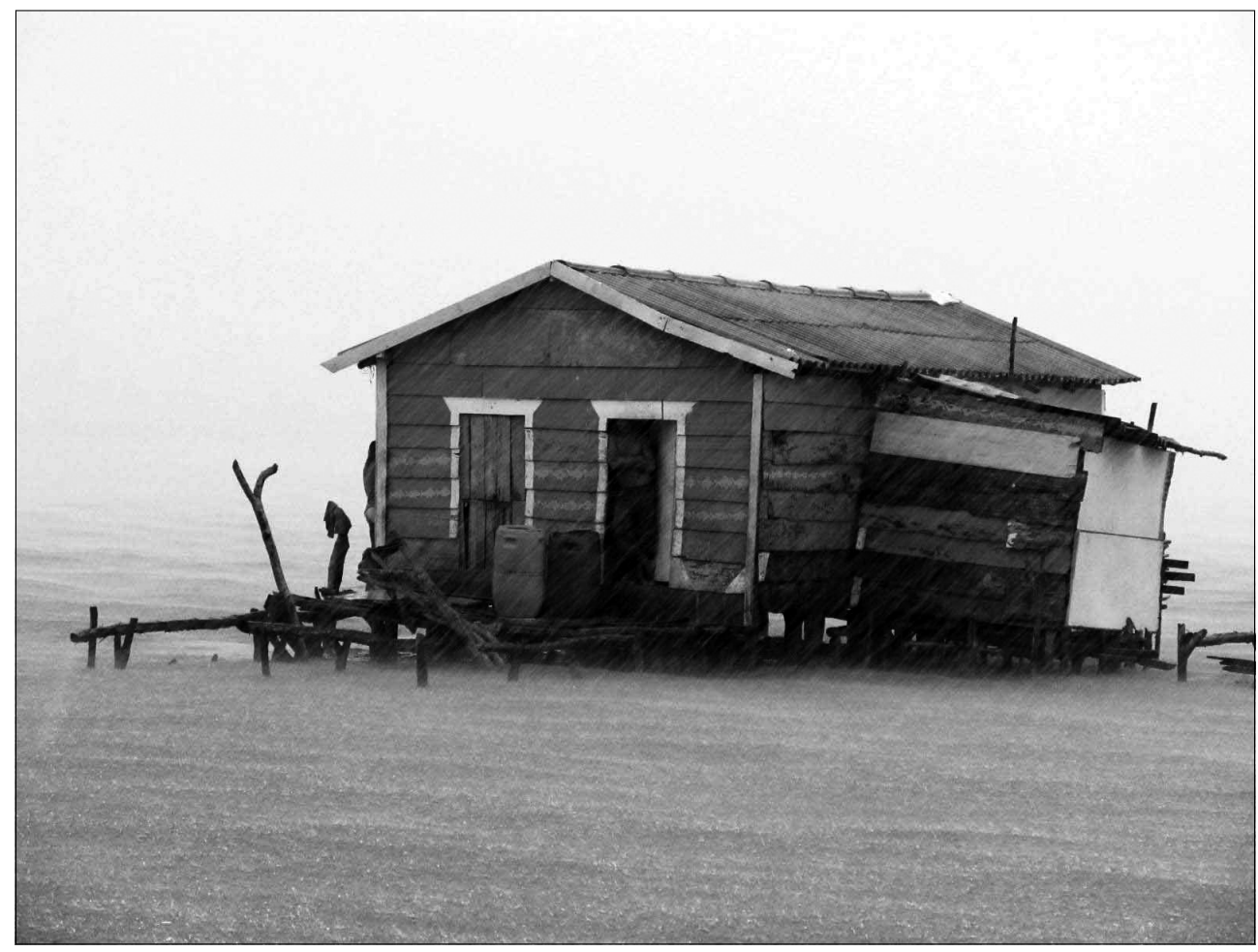

IMAGEN 2.-Tormenta sobre la Ciénaga Grande. 
¿Qué se entiende por una nuda vida? Detengámonos un momento en esta concepción, pues sólo así podrá entenderse el tipo de existencia al que se ha visto abocado el desplazado forzado, incluso antes de que la violencia directa se cruzara en su camino. El origen del empleo que Giorgio Agamben hace del término se encuentra en una figura del derecho romano: el homo sacer. Este personaje, que puede traducirse como el hombre sagrado, pero también como el hombre maldito, es una figura creada para resolver un problema en el que se cruzaba lo sagrado-religioso y lo político-público. Frente a la cuestión de qué hacer con un hombre que cometía un delito cuyo castigo era la muerte, pero quien, por su alta posición como figura religiosa, no podía ser muerto por el poder soberano, se creó precisamente la figura del homo sacer: una vida expuesta a recibir la muerte impunemente. El homo sacer no podía ser muerto por el poder soberano, pero quien le asesinara no recibiría castigo por ello. Dice Agamben entonces que a este hombre (simultáneamente sagrado y maldito) sólo le queda su vida desnuda, su nuda vida, pues estaba privado ya de cualquier relevancia política.

Ahora, volviendo a la Ciénaga Grande de Santa Marta (y a los muchos lugares que como éste estuvieron - y están- en el camino de los ejércitos que adelantan la guerra en Colombia), las personas que allí viven han enfrentado históricamente la precariedad social de su existencia precisamente sólo con su vida desnuda; no ha habido allí nunca una materialización de eso que la constitución colombiana llama un "Estado social de derecho": centro de salud permanente sólo hubo durante un breve periodo, cuando un médico de Barranquilla (la ciudad más cercana), por iniciativa propia, decidió atender allí pacientes los fines de semana en la misma casa donde solía ir a descansar; el agua que se bebe y con la que se cocina proviene de un río en el que se vierte el mercurio y el cianuro de la minería en Colombia; el alcantarillado es la propia ciénaga sobre la que se levantan las casas. Como me dijo un pescador una tarde viendo precisamente la casa del que fuera el centro de salud, abandonada y a punto ya de caerse: "ese es el Estado".

Pero también frente a la arremetida de los actores armados, los habitantes de los lugares apartados del país sólo han tenido su nuda vida para defenderse; han estado ellos también permanentemente expuestos a recibir impunemente la muerte (lo que no pocas veces, como en Nueva Venecia, se ha concretado). Justo de esto hablaba un pescador con el que muchas veces me sentaba a hablar al final de la jornada:

(...) eso fue lo que pasó... eso fue lo que pasó, esa represión que cometen los grupos ilegales en Colombia, es con eso, con el fin de desestabilizar al país, "desestabilizan al país", pero el país también les muestra una vaina. El Estado colombiano también les dice: "bueno, ustedes cometen esta vaina. A nosotros esa gente no nos interesa". O sea que han podido cometer esta masacre y otras diez más y el Estado no se hubiera mosqueado por eso. Mira tú, lee tú el proceso, dale tú una lectura seria al proceso y veras tú que el resultado de lo que encuentras es eso. ¿Estás entendiendo? Bueno... eso es represalia, es una represión del Estado... es represión, ¿ya?: «no, es que la actuación de los grupos paramilitares, o de los grupos de derecha o de izquierda, es una represión contra el Estado colombiano". Pero el Estado a la vez dice, dice el Estado mismo, sin decir una sola palabra, les está diciendo a los mismos delincuentes: "es que a mí esa vaina no me interesa, tú puedes llegar y matar a toda la población”. Le importa una mierda esa vaina. Ese es el mensaje, no hay otro mensaje. 
La vida previa al impacto de la violencia y el impacto mismo -por supuesto- han constituido entonces la existencia en tanto nuda vida. Pero más aún, la asimilación del fenómeno del desplazamiento, por parte del entramado institucional, no ha hecho más que reforzar ese tipo de existencia: es sólo en tanto individuos nudos, en tanto bumanos, demasiado bumanos (Nietzsche), como las víctimas han sido incorporadas al sistema normativo estatal de atención, protección, consolidación y estabilización de la población desplazada. En tanto tal, han sido objeto básicamente de ayudas humanitarias y de reparaciones económicas, que han terminado por reforzar precisamente la condición de precariedad (social y económica sí, pero fundamentalmente política) en la cual han quedado debido al proceso que culminó con el desplazamiento. Es por esto por lo que Liisa Malkki (1997: 234) caracteriza a los desplazados (y a los refugiados) como "sujetos humanitarios universales", esto es, sujetos que una vez han sido desposeídos de realidad política sólo les queda su humanidad.

Existe entonces una cierta alianza entre las fuerzas que expulsan a los desplazados y la institucionalidad que los atiende. No la alianza instrumental que eventualmente pudiera haber entre organizaciones armadas ilegales y ciertas instituciones del Estado (o al menos, ciertos miembros de dichas instituciones) para cometer acciones conjuntas $^{5}$. Pero no es esa alianza instrumental de la que hablamos, sino una de orden hermenéutico que está determinada por el hecho de que la consideración que se tiene del sujeto desplazado dentro de la institucionalidad estatal no difiere mucho de aquella que del mismo sujeto realizaba el perpetrador (o las tramas perpetradoras) del desplazamiento mismo.

El perpetrador se ha enseñoreado precisamente sobre el cuerpo nudo de sus víctimas. Los repertorios de violencia que están en el origen inmediato del desplazamiento (entre ellos la masacre, que ha sido la modalidad predilecta de los paramilitares) tienen una función de teatralización de la violencia con un sentido aleccionador (CNMH 2013). Tal lección consiste, por una parte, en lograr una reputación de violencia que produzca terror, pero también en mostrarle a los pobladores que ellos están inermes frente a su accionar, que no son parte de una comunidad política que pueda protegerlos y que incluso lo único que creían tener, su humanidad (literalmente desnuda) les pertenece a ellos, a los perpetradores. Es en este sentido que podemos entender que una víctima lo es menos por su inocencia que por su indefensión (GMH 2009: 119). El victimario entonces pone a la víctima en una situación en la cual lo único que ésta puede hacer (infructuosamente) es rogar porque su nuda vida reciba ayuda y protección. De forma brutal, la víctima descubre que no es un sujeto de derecho sino un individuo que sólo siente (muy humanamente, en el sentido más literal de este término) temor y temblor, para usar la inquietante y bella expresión de Kierkegaard.

Ahora, si el perpetrador pone entonces frente a la víctima el espejo de su propia humanidad, para mostrarle que no es un sujeto de derechos, es decir, no es un sujeto político, la institucionalidad (en su intervención post-violencia) no hace más que afianzar esa imagen, pues al despojar de toda relevancia política al desplazamiento (como quedó dicho arriba), promueve la emergencia de individuos que interiorizan

\footnotetext{
${ }^{5}$ Este tipo de alianza, que efectivamente ha existido, ha sido probada incluso en estrados judiciales internacionales, donde el estado colombiano ha sido condenado por su colaboración en masacres paramilitares.
} 
dicha despolitización en beneficio de una concepción humanitaria de su existencia; existencia convertida por esta vía, como dice Agamben (2010 [1995]: 169) en "objeto de ayuda y protección", que es justo en lo que lo había transformado previamente el perpetrador con su acto.

No es entonces, como sugiere Castillejo (2000), que las políticas para confrontar el desplazamiento hayan deshumanizado a los sujetos de intervención para poder convertirlos en objetos de control, sino que ha sido precisamente reforzando su humanidad (o desnudándolos políticamente y dejándolos sólo revestidos de ésta), como el sistema de intervención ha operado la transformación sobre la población desplazada. Las políticas de intervención nacen así como políticas humanitarias, concentradas en atender lo inalienablemente humano, esto es, los cuerpos despojados de los desplazados, no en revertir dicho despojo y convertirlos en sujetos de derechos.

Es entonces en tanto ser despojado que el desplazado (y en general, la víctima) empieza a quedar atrapado en las matrices institucionales (Escobar 1995) o redes administrativas de la burocracia estatal (Malkki 1997). Se trata así de potenciales actores sociales transformados en (o reducidos a) problemas (issues) de derechos humanos (McLagan 2006: 191). En tanto problema objeto de intervención, requiere en primer lugar de un ordenamiento especial (también espacial) que constituye en sí mismo una rejilla de observación que determina cómo habrá de entenderse el problema y quiénes son el objeto de tal ordenamiento. Este ordenamiento podemos llamarlo con Giorgio Agamben una "Ocupación del afuera", en la medida en que se trata de un ordenamiento de la excepción de aquellos que han estado "abandonados por la ley" (Agamben 2010 [1995]: 32).

\section{NATURALIZACIÓN DEL DESPLAZAMIENTO}

Ahora, ¿cómo se ocupa ese afuera? ¿Cómo se incorpora al desplazado dentro de las redes administrativas del Estado? El Registro Único de Población Desplazada (RUPD) ha sido el núcleo de esa matriz institucional de intervención ${ }^{6}$. La inscripción en el RUPD ha determinado el ingreso de una persona dentro de la categoría de 'desplazado'. Existe así una ruta del desplazamiento marcada por las instituciones donde los que huyen deben censarse y registrarse para estar certificados como desplazados, esto es, para ser desplazados y poder así aspirar a recibir los beneficios que dicha condición promete garantizar. Estas instituciones constituyen centros nodales en el proceso de construcción del sujeto/objeto desplazado, pues es en ellas donde tienen lugar las tecnologías de clasificación y burocratización que transforman una devastación ontológico/política en un problema administrativo/humanitario.

Las Personerías Municipales, las Defensorías del Pueblo, las Unidades de Atención y Orientación a la Población Desplazada (UAO), las oficinas de los enlaces municipales de las víctimas del desplazamiento forzado, la Unidad de Atención a Víctimas

${ }^{6}$ El RUPD fue creado por la ley 387 de 1997. Se realiza mediante la declaración de los hechos por parte de la población desplazada. Este registro fue reemplazado por el Registro Único de Víctimas, creado por la ley 1448 del 2011. En esencia, se trata de un mecanismo similar, sólo que en el último caso se lleva el registro no sólo del desplazamiento sino también de otros hechos victimizantes asociados al conflicto armado. 
del Departamento para la Prosperidad Social (DPS), incluso las esquinas donde los 'tramitadores' prometen gestionar rápidamente 'las ayudas', son las instituciones y los espacios donde los cuerpos de los desplazados van experimentando unos procedimientos administrativos que terminan por naturalizar su condición.

Dentro de este régimen de intervención, los documentos que prueban que una persona es desplazada no sólo son una herramienta administrativa de vinculación al sistema institucional de representación del desplazamiento, sino que se convierten en el documento de identidad por excelencia de su poseedor. El RUPD es lo que le otorga realidad a un sujeto dentro del funcionamiento del sistema y sólo así le permite moverse dentro de él. Es por esta razón que tener problemas con el registro (la no figuración dentro de él o la exclusión del mismo) significa no sólo no-estar-registradoscomo-desplazados, sino no-ser-desplazados. La representación es más real que la propia realidad ya que sus efectos tienen consecuencias inmediatas sobre la existencia actual de los sujetos clasificados (o no) como desplazados.

Ana es una mujer que ha tenido que huir varias veces de la violencia. Cuando la conocí vivía en un pueblo justo al lado de la Ciénaga Grande, donde había llegado huyendo después de la incursión armada paramilitar en el poblado semipalafítico de Trojas de Cataca, a comienzos del año 20007. Ese sería su segundo desplazamiento, pues allí, a Trojas, había también huido luego de que los paramilitares la expulsaran a ella y a su familia de unas tierras que tenían en la región. En el pueblo donde vivía cuando la conocí fue asesinado su compañero sentimental poco después de llegar allí. Pese a su historial, Ana no es una desplazada forzada por la violencia; y no lo es porque no ha tenido éxito al tratar de realizar el registro que la reconocería como tal. En su pequeña casa donde convive con los varios nietos que le han ido trayendo sus hijos, recordaba su infructuoso intento para obtener el registro:

Bueno, le diré en confianza, que ayuda únicamente me pagaron la reparación administrativa (por la muerte de su compañero sentimental). ¡Pero he recibido tanta ayuda que yo no tengo siquiera un papel que me identifique como desplazada! No señor. (...) Yo fui a la Defensoría del Pueblo aquí a Santa Marta e hice mi declaración. Y total, me la tomaron. Un día yo dije: "yo voy a ver si yo de verdad soy desplazada". Fui a la oficina y me dijo el señor (el personero): "oiga, ¿y usted qué día declaró?» Le dije: "yo declaré el 3 de noviembre del 2008". Me dijo: "le va a tocar volver declarar, porque usted no tiene nada. (Risas) Le dije: "ino sean tan pendejo usted! Que voy a declarar yo otra vez ni que nada, yo tengo mucho oficio pa' hacer en mi casa". Y por esa sencilla razón no tengo ningún solo papel que me acredite que yo soy desplazada.

Estar en el Registro es entonces "lo que vale", en palabras de Ana. Como ella no está allí, significa esto que no ha logrado transformar el hecho (del desplazamiento) en un derecho de reconocimiento (por ser desplazada). No estar en el registro es estar perdido en el umbral que va del hecho político (el desplazamiento) al derecho jurídico/administrativo (la condición oficial de desplazamiento). Los individuos por ello se afanan por lograr aparecer en el registro, pues es gracias a ese documento como pueden empezar a existir - a valer - para el Estado, como pueden empezar a recibir de él unos mínimos: las 'ayudas' humanitarias, los subsidios o las reparaciones en metálico que eventualmente les entregan.

\footnotetext{
${ }^{7}$ En esa masacre murieron 7 personas y fue el preludio de la que sucedería 10 meses después en Nueva Venecia.
} 


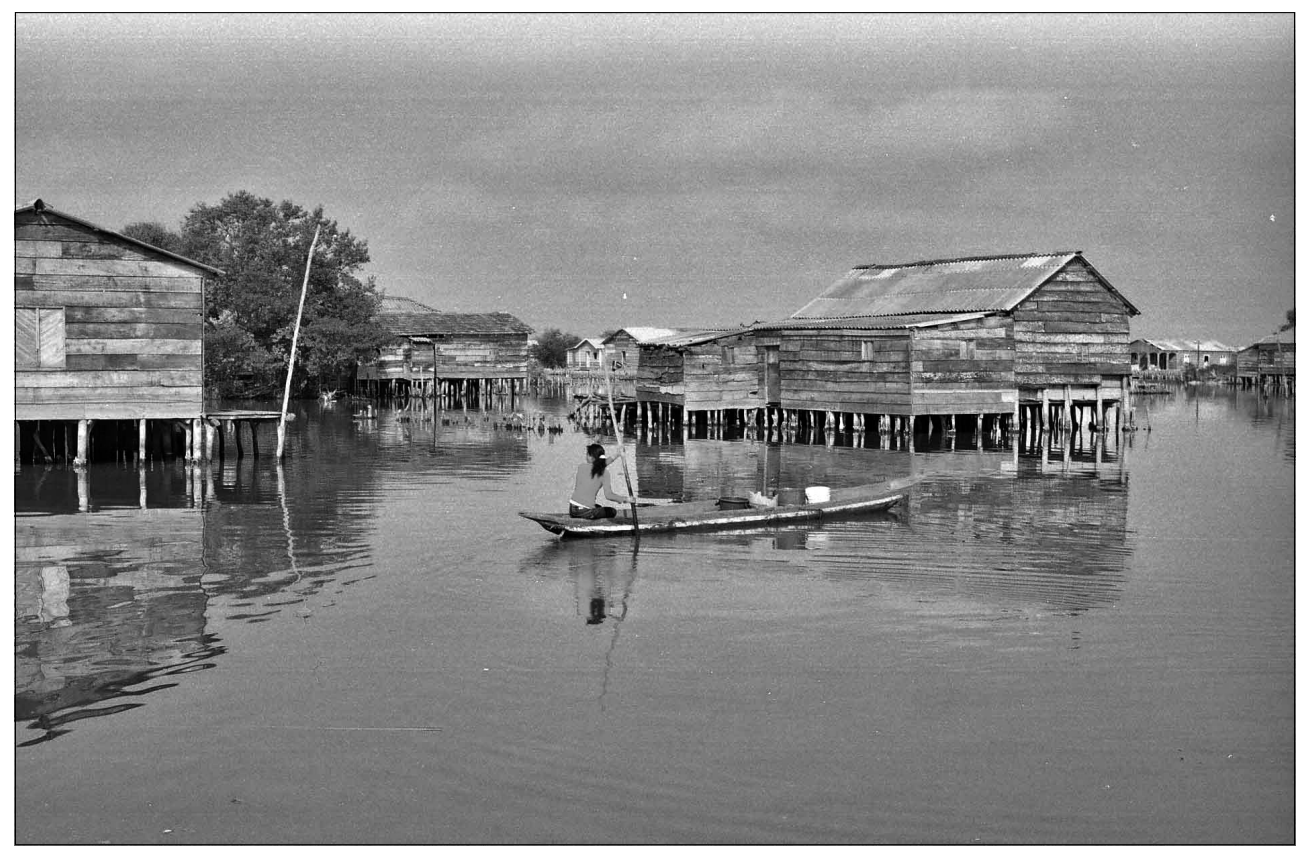

IMAGEN 3.-Remando en Nueva Venecia.

Dentro del sistema complejo moderno que representa este registro no vale entonces el hecho de que efectivamente la persona haya tenido la experiencia traumática de la victimización/desplazamiento, sino que es exclusivamente la habilidad para moverse dentro del sistema y obtener la respectiva certificación lo que realmente cuenta. ¿Cómo no recordar a Bernardo en este punto? Es un hombre al que conocí como desplazado en el desarrollo del trabajo de campo y del que después supe que había inventado la historia que me había contado. En los alrededores de la Ciénaga, donde vivió sus últimos años, Bernardo era bien conocido entre las familias que se habían asentado en esa zona en los tiempos de la expansión paramilitar en la Ciénaga Grande. Se autodenominaba historiador y juglar; a él llegué buscando unos versos de su autoría sobre la masacre de Trojas de Cataca. Una entrada del diario de campo muestra lo relevante que Bernardo llegó a ser para la concepción del desplazamiento que entonces estaba elaborando:

Diario de campo. Septiembre 17 de 2011, Barranquilla, Atlántico (fragmento)

Estuve hoy revisando material de investigación periodística sobre el desplazamiento de la Ciénaga Grande de Santa Marta. Me llamó la atención particularmente uno de los textos que leí, publicado en el año 2001. El escrito, que buscaba explicar los móviles de la incursión paramilitar en la Ciénaga, tenía como eje narrativo la historia de una familia desplazada de Trojas de Cataca (Bocas de Aracataca). Lo que me llamó la atención no fue lo referido a tales móviles, pues no había allí ninguna revelación que me resultara desconocida; mi atención se centró en esa familia protagonista del relato. Estaban en él como ejemplo de la victimización del desplazamiento y una fotografía suya ilustraba el artículo. 
Precisamente a ellos los había conocido unos meses atrás en Ciénaga, Magdalena. Entrevisté a Bernardo, el mayor de ellos, varias veces al principio del trabajo de campo; empecé a construir con su relato un poco también la base de mi etnografía en la Ciénaga, hasta que descubrí, por otras fuentes confiables, que su historia no era real, que había salido del palafito algunos años antes de las incursiones armadas del 2000 y que aprovechando la llegada masiva de población desplazada por las masacres paramilitares de aquel año se había inscrito, junto con su familia, como población desplazada. Hasta el día en que esto escribo siguen ellos figurando como tal en el Registro único de Población Desplazada (RUPD), la herramienta administrativa creada en 1997 para sistematizar la información sobre el desplazamiento forzado en Colombia.

Pero inclusive después de saber esto, seguí frecuentando a Bernardo. Aunque ya había cotejado por diversas fuentes la nula veracidad de su historia (en lo que respecta al desplazamiento), jamás lo confronté con lo que sabía. Dejé que me contará una y otra vez su relato del día en que salió desplazado y que me hablara — lo que me resultaba más interesante- sobre su situación actual, sobre la forma en que está vivenciando su experiencia de desplazamiento. Su experiencia, la de desplazado, es en cierta forma real ya que no sólo se ha asumido como tal (como desplazado), sino que además lo es legalmente, pues para el aparato burocrático institucional lo que cuenta es estar inscrito en RUPD. Hasta tal punto ha asumido Bernardo su rol de desplazado, protegiendo su inscripción en el RUPD, que cierto día me contó los problemas que tenía ya que no lograba que le autorizaran una cirugía que necesitaba pues se había retirado como beneficiario del seguro médico que su hijo tenía en el trabajo. Al preguntarle por qué lo había hecho, me contó que le habían advertido que estar inscrito a la seguridad social le quitaba el derecho a seguir figurando en el RUPD y que por eso había decidido retirarse ${ }^{8}$.

El caso de Bernardo abrió interrogantes que terminaron determinando el rumbo de la investigación, pues aunque contrastándolo con la definición de desplazado dada por la ley - e incluso con el sentido común- el suyo no es un simple caso de engaño y falsificación de testimonio, su situación es más compleja. En efecto, si entendemos la acción armada que produce el desplazamiento masivo de las poblaciones rurales como un acto culminante de una larga saga de violencias interconectadas que desde mucho antes afectaban a los pobladores de estas márgenes, ¿no sería entonces de cierta forma también un desplazado aquel que huyó antes de ese acto culminante debido a las condiciones en las que precisamente vivía? Asumiendo que Bernardo haya abandonado su pueblo por razones asociadas a las condiciones estructurales que allí tenía, ¿no podríamos entender que también fue 'forzado' a abandonar su territorio? ¿No era acaso "vulnerable" su vida desde antes de la incursión armada y no constituyó ésta, de hecho, la confirmación de tal vulnerabilidad?

Los interrogantes se plantean también en otro orden: ¿No pasó Bernardo de ser un objeto constituido por un sistema de control institucional/burocrático (el RUPD) a un sujeto cuya identidad está determinada precisamente por lo constitutivo de ese sistema? En lugar del sujeto preceder al objeto (de intervención), ¿No es Bernardo un ejemplo de alguien que se constituye como sujeto sólo en la medida en que es objeto de una política pública? ¿Son acaso tan poderosos los estímulos del sistema para buscar estar dentro de él y construirse -y sostener por años- una historia —una

\footnotetext{
${ }^{8}$ Pocos meses después de finalizar el trabajo de campo me enteré que Bernardo acababa de morir. De las razones de su muerte no me dieron noticias, pero aún me sigo preguntando si estarían relacionadas con esa operación que precisaba y cuyo trámite se le complicó al preferir seguir inscrito en el RUPD en lugar de estarlo en el sistema de seguridad social.
} 
vida - paralela que encaje con los requerimientos de dicho sistema? ¿No será acaso que el sistema de registro y control de población desplazada no está sólo objetivando una población sino que las está brindando una forma - precaria- de producción de subjetividad?

Y aún más: ¿No son acaso Bernardo y su familia más desplazados que Ana, quien no tiene ningún solo papel que la acredite como tal? Podemos decir que en términos institucionales/normativos efectivamente sí lo son, pues su condición es más real (o tiene más efectos de realidad) que la de aquellos que — como Ana - no han podido encontrar el lazo que los une al sistema. Frente a quienes no han podido transformar su situación de hecho en una condición de derecho (Caso Ana), están los que han logrado esto último sin necesidad de haber experimentado lo primero (caso Bernardo).

La existencia de Bernardo revela que los problemas de tipo político y jurídico que surgen al momento de definir quién es un desplazado los resuelve el propio sistema mediante una respuesta operativa: lo es aquel que pueda probarlo mediante el documento respectivo?. Su caso particular nos pone además frente a los individuos que efectivamente han convivido largamente con la violencia estructural y/o la cotidiana (según las categorías de Bourgois 2005), pero que no han habitado el espacio/tiempo de la incursión armada de alguno de los ejércitos expulsores. Aunque son aquellas las violencias que están en el origen del desplazamiento, es sólo el impacto de la violencia armada directa la que cuenta normativamente como justificante del inicio de la condición oficial de desplazamiento. Quien pretenda ser reconocido como desplazado/víctima debe probar no su sometimiento a las tramas de violencias continuas sino la pertenencia a una población que haya estado en la ruta del avance criminal de los ejércitos armados que desarrollan la guerra en Colombia ${ }^{10}$.

La intervención post-conflicto del Estado (con la particularidad que tiene para el caso colombiano —-donde el conflicto continúa- el término 'post-conflicto') ha moldeado el espacio social donde habita la comunidad intervenida, transformándolo efectivamente en un espacio de desplazamiento. Se trata de representaciones administrativas cuyos efectos de realidad son incluso más importantes (para los individuos que habitan estos espacios) que la propia realidad fáctica. En este sentido, una población no es desplazada sólo porque (o sólo cuando) ha tenido que abandonar forzosamente su territorio geográfico para vivir en otro espacio, sino que lo es en tanto es atravesada por las redes administrativas del desplazamiento a través de las cuales interioriza (o asume) dicha condición. En cuanto al accionar de los grupos armados, el desplazamiento es un acontecimiento que tiene lugar en un momento concreto como resultado de una saga invisible que le precedió; pero el desplazamiento es también una condición que deviene a medida que las redes institucionales de administración de la

\footnotetext{
${ }^{9}$ Para una ampliación teórica de esos problemas políticos-jurídicos, ver Cohen, 1994.

${ }^{10}$ Existe por esto la categoría de "desplazamiento masivo" dentro de la normativa institucional, que aplica cuando debido al mismo acto se desplazan mas de 10 familias o 50 personas. En este caso, a un individuo le basta con declarar que vivía en la población cuyo desplazamiento haya sido catalogado como 'masivo' para ser considerado desplazado, con total independencia de si esa persona particular efectivamente se desplazó. Es este el caso de Nueva Venecia, donde varios de sus habitantes actuales no abandonaron el pueblo después de la masacre o estaban temporalmente fuera de él cuando aquello ocurrió (y regresaron pocas semanas después como lo tenían previamente establecido) y sin embargo son considerados desplazados dentro de la institucionalidad estatal.
} 


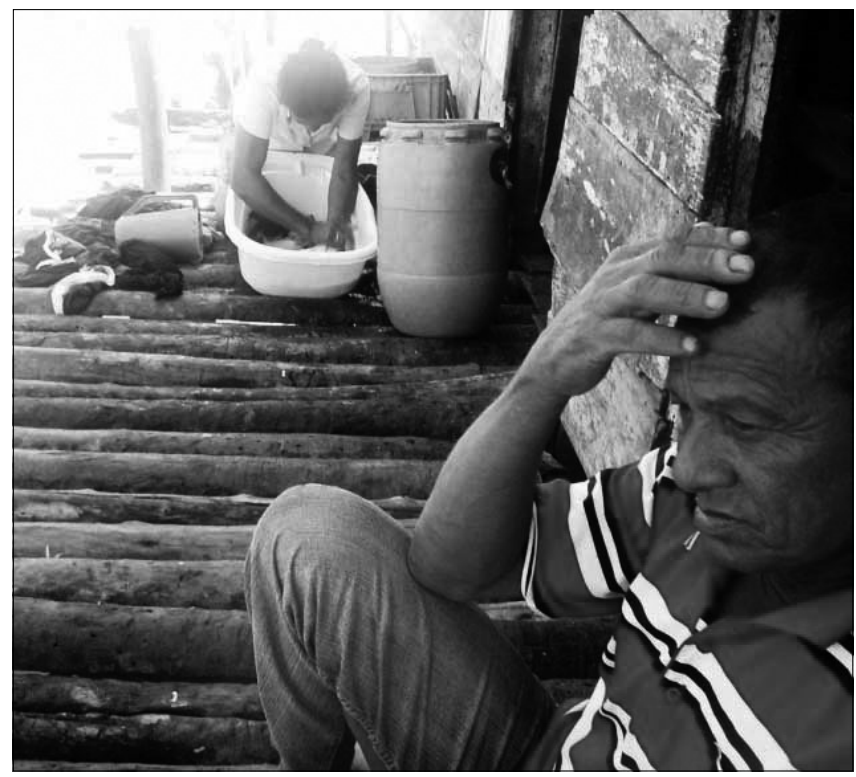

IMAGEN 4.-Contando el desplazamiento.

excepción penetran en las tramas cotidianas de una población. La observación de la población de Nueva Venecia nos posibilita precisamente adentrarnos en esta tesis.

La población que allí habita no está desplazada porque ésta sea su situación fáctica, puesto que viven en el mismo espacio geográfico donde ha habitado siempre. Como acontecimiento entonces, el desplazamiento forzado tuvo una duración relativamente corta para la población: unos pocos días para algunos y cuestión de meses para la mayoría (están también los que nunca se fueron y también, por supuesto, algunos que nunca regresaron). Pero la población ha devenido desplazada desde el momento en que se estableció su caso como el de un desplazamiento masivo y entró por tanto dentro de la normatividad de excepción que analizamos al principio. Este devenir-desplazamiento comenzó, paradójicamente, a partir del retorno: desde el momento en que fue considerada oficialmente como desplazada, la población se vio impelida (incluso compelida) a moverse a través de las dinámicas burocráticas de administración institucional para este sector poblacional. Este movimiento constituye una paulatina asunción del estado de excepción como forma de ser-en-el-mundo, a través de la incursión de estos individuos en el sistema de administración y control de su condición.

\section{LOS SISTEMAS EXPERTOS Y EL DESANCLAJE DE LA JUSTICIA}

Justo después de la masacre paramilitar tuvo lugar en la zona una intervención humanitaria, que comenzó en los refugios de desplazamiento en el municipio de Sitionuevo (el centro urbano/administrativo al cual pertenece Nueva Venecia) y que 
se ha prolongado después en el propio palafito, confundiéndose —como quedó dicho al principio - con las intervenciones también de carácter humanitario que se han dado por desastres naturales. Después vendrían los primeros proyectos productivos que buscaban cumplir con la "estabilización socio-económica" ordenada por la ley. Por último, a partir de la puesta en marcha de la Ley de Justicia y Paz (2005), han tenido lugar medidas de reparación con un predominante componente económico, especialmente a partir de la creación de las reparaciones vía administrativa (2008).

A esta intervención del Estado posterior a la masacre paramilitar, hay que sumarle la presencia en la zona de organismos internacionales (especialmente agencias de la ONU: primero la Agencia de las Naciones Unidas para los refugiados, ACNUR y últimamente la Oficina de las Naciones Unidas contra la Droga y el Delito, UNODC), distintas ONG, organizaciones religiosas, centros de investigación, organismos judiciales, oficinas de abogados, etc. Los funcionarios y representantes de estas entidades y organizaciones empezaron a formar parte del paisaje itinerante de la Ciénaga, transformándose en los elementos visibles del andamiaje institucional/corporativo que se ha levantado alrededor de los pobladores del palafito.

Esta presencia institucional post-retorno se ha dado a través de la emergencia de sistemas expertos (Giddens 2011 [1990]), que han obligado a los pobladores a seguir procedimientos modernos complejos, establecidos y sistematizados por esas instituciones, para acceder a programas y servicios cuya fiabilidad y riesgo están des-localizados: los programas y servicios que regulan los sistemas expertos dependen de estructuras orgánicas complejas, todas ellas burocratizadas e impersonales, que superan por esto mismo cualquier tipo de relación interpersonal que eventualmente establezcan los pobladores con los representantes de esas instituciones en el terreno.

Tratemos de entender lo anterior: las relaciones en el palafito (económicas y sociales fundamentales) han estado históricamente determinadas por la presencia del otro con el cual se tiene la relación. La confianza y los riesgos de las relaciones (en una transacción comercial de pescado, por ejemplo) han estado siempre localizadas allí mismo, es decir, han dependido por entero de las personas relacionadas. Esto es a lo que nos referimos al hablar de relaciones localizadas: podrán ser exitosas o no, pero han dependido completamente de los directamente implicados en la relación allí donde ésta ha tenido lugar. Pero en el caso del sistema experto de la intervención institucional que ha llegado al palafito desde el retorno, la confianza y los riesgos de las relaciones que los pobladores establecen con los representantes de esa institucionalidad no dependen de factores que puedan controlarse en el terreno por aquellos que directamente se relacionan. Hay unos representantes institucionales en el terreno, sí, pero ellos son precisamente eso: representantes de un sistema que está por encima de ellos y que es el que finalmente decide. Es por esto que, en este sentido, la comunidad ha pasado de ser un lugar de relaciones localizadas a "una expresión localmente situada de relaciones distantes" (Giddens 2011 [1990]: 106). La "expresión localmente situada" es la relación directa entre pobladores y funcionarios, pero la verdadera relación no es con ese funcionario sino con la institución que él representa, la cual precisamente se encuentra "distante".

Las reparaciones por la masacre y los propios procesos judiciales derivados de ella (o de los asesinatos selectivos y desapariciones que le siguieron), han sido llevados a cabo precisamente a través de la introducción de sistemas expertos en el tejido 
cotidiano local ${ }^{11}$. Los jueces, fiscales y abogados, así como los personeros municipales y los representantes de ONG que asesoran a las víctimas en estos temas (también los funcionarios de la Unidad de Atención de Víctimas adscrita al DPS), son todos detentadores del conocimiento experto que se requiere para moverse a través de la red administrativo-burocrática de leyes, decretos, audiencias públicas, declaraciones, sentencias, demandas, y todos los demás instrumentos y procedimientos jurídicos y administrativos involucrados en el proceso de confrontación de las violaciones de los DDHH que allí tuvieron lugar.

No poseer el conocimiento experto que se requiere para trazar e interpretar una hoja de ruta que guie los movimientos a través de dicha red constituye, para las víctimas, una vía hacia el estancamiento en la literalidad del acto de victimización (Jiménez 2010: 167), pues se pierde toda posibilidad de acceder a mecanismos que tienen una potencial capacidad reparadora y/o que vehiculan formas de justicia que pueden subsanar hasta cierto punto precisamente esas injusticias del pasado. Aunque la justicia transicional sea un modelo de justicia "imperfecto para tiempos imperfectos" (Uprimny 2013), puede tener ésta efectos reparadores si a través de su aplicación la experiencia de horror de las víctimas escapa de la banalización o sacralización y adquiere, por el contrario, una dimensión ejemplar que permita ser una herramienta de restitución (o creación) de una comunidad política (cfr. Todorov 2002; Todorov 2008 [1995]). Pero para que esto pueda darse se requiere, en primer lugar, que las víctimas logren descifrar la forma en que opera el sistema experto de la justicia, ya que de otra forma encontrarán barreras operativas que les impedirán recorrer esa senda imperfecta — pero aún así significativa- de la justicia transicional.

Nueva Venecia ha sido una población aislada de pescadores. El acceso al pueblo es difícil (sólo posible a través de caños que van del río Magdalena hasta la Ciénaga Grande) y sus pobladores han aprendido a vivir básicamente a través de relaciones interpersonales con sus familiares, compadres y vecinos. Esos mismos pobladores son los que después del retorno (o incluso estando aún en sus lugares de refugio) empezaron a ser atraídos hacía el sistema para que realizaran los registros necesarios y oficializaran su estado, como desplazados o como familiares de víctimas mortales de la masacre, y los que encontraron precisamente esas barreras operativas que son propias del sistema.

${ }^{11}$ Dentro de una concepción amplia de las reparaciones, a éstas también pertenecen precisamente esos procesos judiciales que buscan asignar responsabilidades por las acciones violadoras de los DDHH que dieron lugar a las reparaciones (dichos procesos harían parte de las medidas de satisfacción que se contempla en el marco internacional de las reparaciones). Pablo de Greiff (2006) defiende, por su parte, un uso restringido del término, referido sólo a las medidas que brindan beneficios directos a las víctimas de los crímenes. La condena de un responsable por el acto de violencia sería un beneficio, sí, pero uno indirecto y por ello no es considerada como parte de las reparaciones por de Greiff. Pero dado que el marco judicial dentro del cual se habían adelantado hasta el año 2012 las investigaciones por las masacres de la Ciénaga Grande de Santa Marta (la Ley de Justicia y Paz), contempla (en su artículo 8) medidas de satisfacción como parte de la reparación, las cuales consisten (entre otras cosas) en el procesamiento de los autores de las violaciones de los DDHH y la búsqueda y difusión de la verdad sobre lo sucedido, consideramos apropiado valernos para nuestro análisis de una concepción amplia del término 'reparaciones' donde este tipo de acciones puedan tener lugar. Para una ampliación de las medidas de satisfacción y de otro tipo que están contempladas dentro del marco jurídico internacional de las reparaciones, ver Falk, 2006; Uprimny y Saffon 2009. 


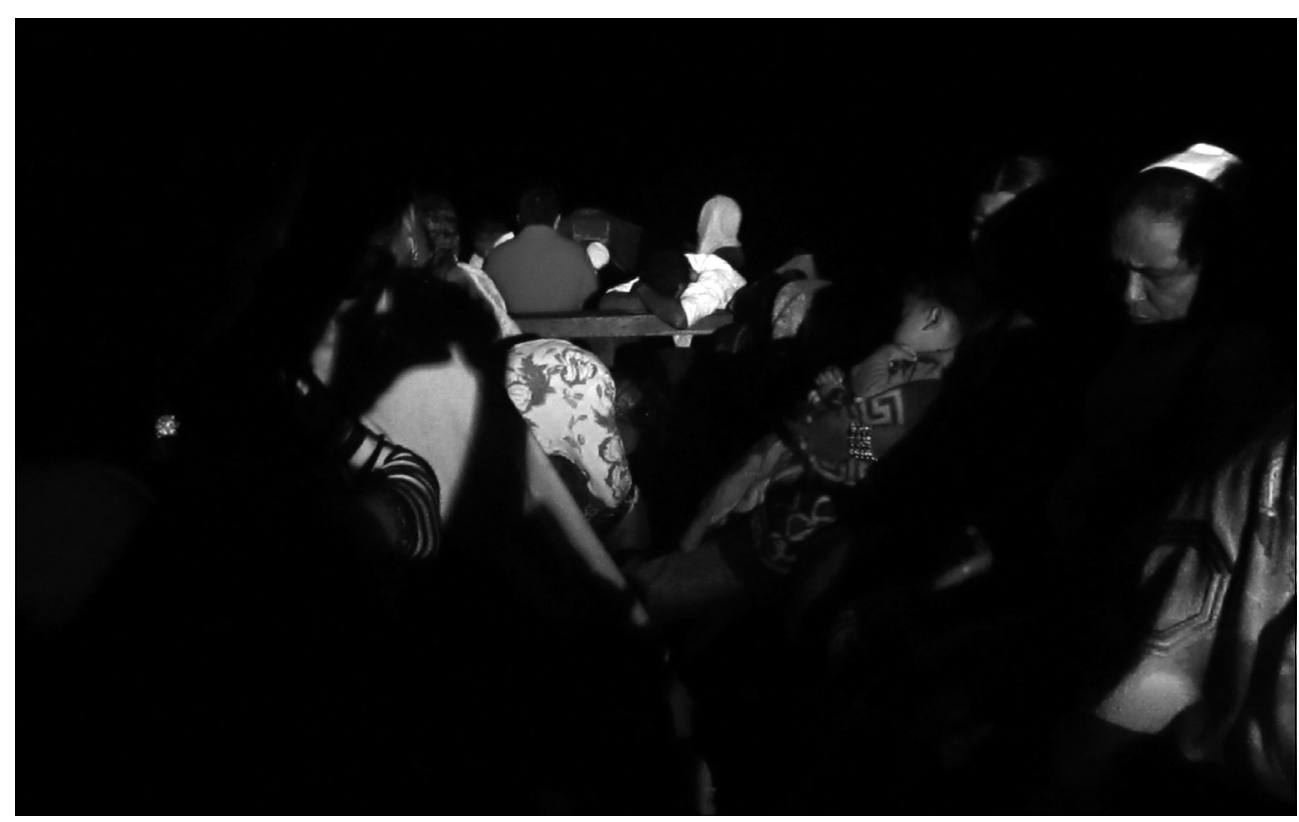

IMAGEN 5.-Atravesando la Ciénaga Grande para recoger "las ayudas”.

Doña Emilse es una de esas personas. Me hablaba de la masacre en su casa a medio construir. Me hablaba de esos hombres armados en el pueblo, de la huida en la canoa y del regreso unos meses después. Había perdido a uno de sus hijos esa noche, pero hasta 10 años después su hijo no figuraría como uno de los muertos de la masacre paramilitar de Nueva Venecia:

—iPero en su momento usted no denunció doña Emilse?

-No, nada, yo no presenté nada.

— ¿No presentó nada hasta el 22 de noviembre del $2010 ?^{12}$

-Ajá.

- ¿Por qué?

- No, porque no hemos sabido declarar.

No saber declarar significa carecer del conocimiento requerido para interactuar dentro del sistema experto judicial. Doña Emilse recibió ayuda humanitaria allí donde se refugió; contó lo sucedido: la incursión paramilitar, la muerte de su hijo; lo hizo reiteradas veces, sólo que no a las personas y en las condiciones requeridas para que su relato fuera oficial. Posteriormente regresó al palafito, desconociendo todavía el procedimiento que debía seguir para adelantar procesos judiciales por lo ocurrido

${ }^{12}$ En esa fecha, como parte del acto oficial de conmemoración de los 10 años de la masacre de Nueva Venecia, se hizo presente en el palafito una comisión judicial de la Unidad de Justicia y paz de la Fiscalía General de la Nación, la cual recogió testimonios de los familiares de las víctimas de la masacre y de algunos otros pobladores. 
(careciendo además de los medios para buscar asesoría legal), así que fue conformándose con lo que el propio Estado le iba brindando: "eso fue lo que recibí, eso es lo que he cogido, eso es lo que me he conformado y con eso es que vivín, me dijo al final de nuestra primera charla.

La entrada en vigencia de la ley 975 de 2005 (Ley de Justicia y Paz) debía introducir, en teoría, nuevas herramientas en el escenario post-conflicto, las cuales podían ser utilizadas por las víctimas del conflicto (y particularmente por las víctimas del paramilitarismo, pues la ley fue concebida para facilitar la desmovilización militar de estos grupos) para acercarse al sistema judicial y hacer valer allí el derecho a la verdad, a la justicia y a la reparación, que eran ofrecidos por la ley en aparente consonancia con los principios internacionales que rigen la justicia transicional. Los mecanismos de esa Ley comenzaron a adquirir expresión local en Nueva Venecia el 22 de noviembre de 2010, cuando un equipo de la Unidad de Justicia y Paz de la Fiscalía General de la Nación llegó al palafito como parte de la conmemoración de los 10 años de la masacre. Aquel día, los funcionarios de la Fiscalía instalaron en la iglesia (epicentro de la masacre) un equipo de proyección audiovisual para mostrarles a los pobladores algunos fragmentos de la versión libre ante los fiscales de Justicia y Paz del señor Rodrigo Tovar Pupo, alias 'Jorge 40', ex jefe del bloque Norte de las Autodefensas Unidas de Colombia, al cual se le atribuye la masacre de Nueva Venecia.

Dicha audiencia pública había tenido lugar en Barranquilla en la semana del 2 al 6 de julio del 2007. Aunque la ley contempla que es derecho de las víctimas asistir a estas audiencias y efectuarle directamente al 'versionado' (esto es, al perpetrador que está rindiendo su versión) las preguntas que consideren pertinentes, fue sólo más de tres años después (cuando el propio 'Jorge 40' ya había sido extraditado a EEUU para responder — exclusivamente- por delitos de narcotráfico) que los pobladores de Nueva Venecia pudieron conocer lo sucedido en la audiencia. Reunidos todos los que cabían en la iglesia, sentados donde podían y soportando el calor, vieron cómo 'Jorge 40' aparecía en primer plano en la grabación de video.

En la proyección, el paramilitar contaba su versión de la masacre: la denominó un "acto de guerra" contra militantes y colaboradores del ELN y reconoció sólo 34 de los 38 asesinados. Añadió que gracias a esa acción las AUC pudieron empezar a desvertebrar a ese grupo guerrillero en el área de la Sierra Nevada de Santa Marta y de los puertos sobre el río Magdalena. Desconocedores de la estructura funcional de una audiencia de versión libre (es decir, desconocedores de la estructura funcional del sistema experto), los pobladores reunidos en la iglesia no entendían cómo podía ser posible que se le haya permitido decir todo esto al mismo hombre que había ordenado la incursión armada en su territorio. Palabras más, palabras menos, lo escuchaban llamarlos a ellos guerrilleros. Crecía la indignación y la física rabia por lo que oían. José Pablo, un pescador que había perdido a tres familiares en la masacre (y de la que se salvó al tirarse al agua y refugiarse bajo uno de los palafitos), no pudo aguantar esa rabia y se paró desde la parte de atrás de la iglesia y caminando entre la multitud se abrió pasó hasta llegar donde estaban los funcionarios que coordinaban la proyección:

Entré yo adentró y miré y estaba la pantalla allá ese ('Jorge 40') hablando. Bueno, yo me le acerqué y le pedí el permiso a los que estaban manejando la vaina. Yo les dije: 
'oiga, compañero, amigo, perdonen, pero esa pantalla deben de prohibirla ahî' - 'Ay, ¿por qué?' - 'porque sí. Porque soy miembro de tres muertos que está diciendo el señor y si por aquí estuvo ese grupo es porque él los mandó. ¿Por qué dice él ahí que no los mandó a la Ciénaga Grande? (...) 'Entonces hágame el favor y suspenda eso un poquito porque estamos sintiendo en el corazón que nos están volviendo a herir'. A varia gente no les quedó bien (no les hizo bien las declaraciones de '40'), estaban llorando... pero yo fui el único que me llegué hasta allá a decírselo, ¿ya? Eso da dolor de ver eso, da temor.

Este primer acercamiento del sistema experto de la justicia transicional dejó de manifiesto que ésta opera también a través de formas de relaciones distantes. La versión libre, que en el saber experto de la ley debía constituir la herramienta para la reconstrucción de la verdad, por ser ella la oportunidad del perpetrador de acogerse a los beneficios de la ley mediante la confesión de sus crímenes, se transformó durante aquella proyección en la iglesia en otro capítulo más de victimización. Al propio desanclaje que representa la mediación de la tecnología en dichas audiencias, se suma el hecho de que éstas son percibidas (por las comunidades víctimas) como instrumentos de legitimización de las justificaciones del perpetrador. En el caso de la proyección llevada a cabo en la iglesia de Nueva Venecia, la total ruptura espacio/ temporal con respecto a la propia audiencia pública (recordemos que la proyección en el palafito se realizó tres años después de realizada la audiencia), reforzó tales mecanismos de desanclaje y distanciamiento, haciendo aún más evidente la revictimización que tal acto implicaba.

La adopción de los principios expertos contemplados en la Ley trajo así como consecuencia elementos que no estaban previstos dentro del propio sistema. La experiencia de la recepción de los mecanismos de aplicación de la ley mostraba así las limitaciones del propio sistema. Este episodio revela cómo los mecanismos de la justicia están por fuera del alcance de la intervención local y debido a ello, por más dolor y temor que las declaraciones del perpetrador produjeran, no había forma de contrarrestarlas al mismo nivel, pues la propia distancia espacio/temporal lo impedía: José Pablo no pudo contradecir al propio 'Jorge 40' y tuvo que conformarse con pedir que callaran su grabación.

En términos de Lyotard (1983), lo que tuvo lugar en la iglesia del palafito (así como, en términos generales, en las audiencias de la ley de Justicia y Paz) fue un diferendo, pues las víctimas de la injusticia de la violencia carecían de instrumentos para comprender el lenguaje del sistema donde se buscaba dirimir el conflicto subyacente, quedando así aquellas reducidas a un rol pasivo de víctimas. El diferendo, como lo define Lyotard, es precisamente un productor de víctimas. Todo esto opuesto a lo que sucede en un litigio (siguiendo aún a Lyotard), donde la víctima de la injusticia sí tiene los elementos para acceder al lenguaje (al funcionamiento) del sistema.

Precisamente ante el desanclaje y distanciamiento espacio/temporal del sistema judicial transicional, otro "cuerpo de expertos" (la expresión es de Jiménez 2008), conformado por abogados defensores de derechos humanos, hizo presencia en la zona con la promesa de transformar el diferendo en litigio, es decir, con la promesa de constituir un espacio donde las víctimas pudieran encontrar ese lenguaje que les posibilitara operar dentro del sistema de la justicia. Pero la intervención de estos actores en el escenario de la confrontación de los efectos del conflicto se ha dado tam- 
bién en clave de sistemas expertos, cuya operatividad es fundamentalmente la misma de aquel al cual se oponen teóricamente, pues también ellos crean relaciones distantes con la comunidad (atenuadas por el hecho de que los 'puntos de acceso' son miembros de la propia localidad) y mantienen un hermetismo no sólo en torno al funcionamiento del sistema, sino incluso a la finalidad del mismo.

Doña Emilse recibió en esa misma casa donde conversamos a representantes de un abogado de Barranquilla que estaba reuniendo poderes firmados por las víctimas de la masacre para interponer una demanda contra el Estado colombiano ante la Comisión Interamericana de Derechos Humanos. Esto último no lo tenía muy claro doña Emilse, pero sí las circunstancias en las que fue contactada:

-Aquí vino compadre A. y un hijo de doña B. y vino el asistente de ese abogado. Y para que le dijera que si yo qué, que si yo cuándo. (...) Nos dijeron a todos los que estábamos, todo el familiar de los que mataron aquí, hasta de Buenavista, aquí del lado de Clarín, del lado de Palermo, todo ese personal estaba. Y nos dijeron: 'no, que tengamos una espera para el dos mil...' —eso fue en el 2009-, 'que tengan para el 2011', y mire ya donde va el 2012 y nada. Ya eso se quedó así no han venido a molestar a uno ni más nada. No se sabe en qué va ese proceso.

- ¿Y esa demanda era ante quién?

— No sé quién me acaba de, de... yo no sé de dónde.

— ¿Y también les pidieron declaraciones? ¿Usted tuvo que ir a declarar a algún lado?

- Nada, aquí vinieron a firmar y nada más.

— ¿Entonces usted no ha tenido contacto directo con el abogado? ¿No tiene el teléfono directo para preguntar en qué va?

—Un hijo mío sí. Él cada rato llama y está aburrido: 'mami, eso está pagado'. También será falso eso.

Después doña Emilse me habló del día en que los fiscales de la Unidad de Justicia y Paz llegaron a su casa a tomarle declaración y pedirle unos documentos que precisaban para la acción judicial. Escuchándola, se percibe la similitud de este encuentro con el de los representantes de los abogados:

-Ahora metí unos papeles, porque vino la Fiscalía. Ellos vinieron aquí preguntando por los familiares de las víctimas, dijeron que metiera unos papeles y fue en Sitionuevo una reunión.

— ¿Y supo para que era el trámite? ¿Le explicaron qué podía esperar ahí?

-No me dijeron nada.

— ¿Y cómo supo que podía ir a meter los papeles?

- Porque aquí vino justicia y paz, aquí a la casa mía llegaron los abogados (los fiscales de la Unidad de Justicia y Paz).

- ¿Y no le dijeron qué podía salir de allí?

- Me dijeron que tenía que esperar porque ellos tenían que viajar. Que les diera un número de teléfono para ellos llamar. Estoy esperando para ver. Voy a ver qué resuelven ellos. Si no resuelven allá...

El mecanismo cómo operan los dos sistemas es el mismo; el desconocimiento con el que los locales participan en él lo es también. No es sólo el funcionamiento el que les resulta desconocido; también el propio objetivo del procedimiento gestionado por el sistema. Así como doña Emilse no sabe qué puede esperar del proceso que se adelanta dentro de Justicia y Paz, tampoco sabe qué puede suceder con los poderes que le firmó al representantes del abogado (quien, por cierto, nunca ha escucha- 
do directamente los testimonios de sus representados). Tiene claro, como todos en Nueva Venecia, que le hablaron de cantidades enormes de dinero como forma de reparación por la masacre, de forma análoga a como tienen claro que a través del mecanismo de la 'reparación administrativa' pueden obtener una cuantía de dinero sin esperar la resolución del proceso judicial ${ }^{13}$. La prevalencia del dinero como el único elemento comprensible del sistema experto para las comunidades, como el único 'lenguaje' común para transformar el diferendo en litigio, convierte así el escenario de la justicia en un escenario transaccional donde el dinero no alcanza una dimensión simbólica (que es la que se espera en un verdadero proceso de reparación), sino que se agota en su dimensión material, en un precio pagado por la experiencia de terror.

El sistema experto opera aquí como un mecanismo administrativo de conservación de la literalidad del acto de victimización. Es así un creador de perspectivas reducidas, pues sustrae de la reparación todos los elementos simbólicos y profundos, dejando sólo la superficialidad del pago como el único terreno en el cual las víctimas de las injusticias pueden esperar ver brotar algún asomo de compensación. Reducidas sus expectativas, empiezan a relacionar (a reducir) todos las demás dimensiones de la reparaciones al pago en efectivo por la experiencia vivida. Es lo que sucede con José Pablo, con el que hablé por varias horas y siempre (siempre) que le mencionaba el tema de la justicia, él entendía que le estaba hablando de reparaciones financieras:

- ¿Y ha habido justicia por lo que pasó aquí?

- Bueno... a ciertas personas lo han pagado y a otras no (...) a los dos hermanos míos también los pagaron, a la mujer también le dieron unos diez millones de pesos $(+/-4000$ euros); y a mi mamá, como ella era mamá del que se fue sin mujer, también le dieron una platica.

La incapacidad de estructurar las demandas de reparación en términos distintos a los pecuniarios no descansa en una apuesta por la inmediatez de la población víctima de las injusticias. Esa apuesta es sólo un síntoma, pues ella es manifestación de lo que con Joe Bailey (1988, citado por Giddens 2011 [1990]: 122) podemos llamar un "efecto amortiguador", que consiste en esa convicción, que se va instalando en un individuo (colectivo en este caso), de que ciertos problemas vitales son, de hecho, irresolubles. Ante la ausencia por años de una reparación integral y la persistencia de las necesidades cotidianas, la confianza en una transformación estructural de la realidad se ha deteriorado y por tanto el dinero, en su materialidad e inmediatez, se impone como alivio temporal para la vulnerabilidad del día a día.

Las reparaciones entonces, las que se esperan del Estado o de otros mecanismos que funcionan paralelo al de éste, han operado de tal forma que han terminado haciendo precisamente lo que Pablo de Greiff previene que no debe pasar en ningún caso con las reparaciones: invitar a que sus beneficiarios las interpreten como un esfuerzo de ponerle precio a la vida de las víctimas o a la experiencia del horror (de Greiff 2006: 466). Una vez interpretadas o asimiladas de esta forma, las reparaciones pierden justamente su capacidad reparativa y se transforman —al contrario- en un

${ }^{13} \mathrm{~A}$ los pobladores se les dijo que en caso de ganar la demanda internacional recibirían entre todos una cantidad cercana a los 30 mil millones de pesos (alrededor de 15 millones de dólares). 
poderoso mecanismo de banalización de la victimización, por cuanto ésta se despolitiza. En este punto, la experiencia de la violencia no logra procesarse para transformarse en generadora de procesos de agencia sino que se agota en lo que con Todorov podríamos llamar su literalidad.

\section{CONCLUSIÓN: OBJETOS DE AYUDAS EN LUGAR DE SUJETOS DE DERECHOS}

Ha manifestado Guillermo O’Donnell (2004: 40) que quizá en ningún otro lugar se revela tanto la privación de las personas vulnerables como en el escenario donde éstas interactúan con las burocracias de las cuales deben obtener algún tipo de beneficio; el escenario donde las personas vulnerables interactúan con los sistemas expertos. Constituye éste un espacio transaccional donde distintas instituciones (estatales y no estatales) ofrecen beneficios asistencialistas, que aunque tienen un restringido efecto coyuntural sobre sus beneficiarios, sí sirven a tales instituciones $-\mathrm{y}$ a la red burocrático-administrativa que inevitablemente se extiende- para exhibir "resultados" ${ }^{14}$.

La población víctima ha sido objeto entonces de una prolongada "ayuda humanitaria" y de una serie de reparaciones con marcado énfasis monetario. Para seguir siendo receptores de esto, las víctimas deben renunciar a seguir procesos que los lleven a superar su condición de victimización, que los lleven a superar realmente el desplazamiento, pues es mediante la permanencia dentro de la situación de excepción como obtienen una atención (mínima) que de otra forma desaparecería. Ya señalaba Olivera (2001: 109) que es precisamente la extrema necesidad en la que vive la población desplazada/víctima la que la deja expuesta a la influencia de las "ayudas". Las ayudas humanitarias y las reparaciones económicas desancladas, adquieren así una dimensión ontológica, esto es, constituyen - para las víctimas - una forma (precaria) de ser-en-el-mundo. Despolitizados y privados de una significación histórica para la experiencia de horror y desarraigo (o reducida esa experiencia a un registro burocrático en una base de datos), los desplazados se aferran a dichas ayudas en tanto último vestigio de su humanidad.

Pero la humanidad propia del discurso humanitario-asistencialista se fundamenta en la idea de una infrahumanidad del otro desplazado (Castillejo 2000), o simplemente de una humanidad nuda: en lugar de un sujeto social complejo, la intervención humanitario-asistencialista crea lo que con el novelista colombiano Manuel Mejía Vallejo (1964: 33) llamaremos "hombres demasiado evidentes", hombres que se confunden con la función que las instituciones (los sistemas expertos) les atribuyen, que en este caso es la de pasivos sufrientes. Las ayudas humanitarias (a las que en la práctica se ha visto reducida la reparación en la Ciénaga Grande, amén del dinero entregado a través de las reparaciones directas vía administrativa) constituyen así un mecanismo para des-complejizar a los individuos, un mecanismo de reducción de sus dimensiones sociales a una existencia en la inmediatez de la supervivencia.

Dice Elisa García (2011: 355) que uno de los inconvenientes que surge del enfoque humanitario con el que se tratan los problemas relacionados con las violencias, es que los fenómenos locales son primero descontextualizados y des-historizados, para

\footnotetext{
${ }^{14}$ El trabajo de Dambissa Moyo (2009) es particularmente revelador sobre esto.
} 
luego ser reinsertados de forma aislada en nuevas realidades creadas. Los sujetos locales que están insertos en ese proceso sufren así una deslocalización ontológica con respecto a su experiencia del horror, es decir, sufren una pérdida de sentido de la experiencia de victimización. Quedan entonces atrapados en un presente continuo de tal experiencia y refuerzan (actualizan) la victimización original con cada nueva intervención, ante la cual no se presentan como sujetos políticos sino como cuerpos nudos, como seres desprovistos de realidad más allá de su humanidad.

Las intervenciones humanitarias (sumadas al impacto de las reparaciones monetarias) son el puente por el que se pasa del desplazamiento como acontecimiento al desplazamiento como devenir. En lugar de políticas para combatir el desplazamiento, lo que se observa de hecho son mecanismos administrativos para interiorizar dicha condición, ya que a través de esos mecanismos el desplazado/víctima adquiere cierta visibilidad ante el Estado, la cual le permite ser el objeto de unas ayudas que no llegarían de otro modo. La existencia de personajes como Bernardo y la propia prolongación indefinida de la condición de desplazamiento dan cuenta de la existencia de esta condición en tanto forma marginal de ser-en-el-mundo. Esta forma de existencia ha sido entonces promovida y alimentada por intervenciones que en lugar de promover la superación de la victimización, han terminado reforzando la literalidad de tal experiencia.

\section{BIBLIOGRAFÍA CITADA}

Agamben, G. 2010 [1995]. "Homo sacer. El poder soberano y la nuda vida". American Anthropologist 108(1): 191-220.

Aparicio, J. R. 2005. «Intervenciones etnográficas a propósito del sujeto desplazado: estrategias para (des)movilizar una política de la representación. Revista Colombiana de Antropología 41: 135169.

Bourgois, P. 2005. "Más allá de una pornografía de la violencia. Lecciones desde El Salvador", en F. Ferrándiz y C. Feixa (eds.), Jóvenes sin tregua: culturas y políticas de la violencia. Barcelona: Anthropos.

Castillejo, A. 2000. Poética de lo otro. Antropología de la guerra, la soledad y el exilio interno en Colombia. Bogotá: Instituto Colombiano de Antropología e Historia (ICANH).

Centro Nacional de Memoria Histórica (CNMH). 2013. jBasta ya! Colombia: memorias de guerra y dignidad. Bogotá: Imprenta Nacional.

Cohen, R. 1994. "International Protection for Internally Displaced Persons: Next Steps". RPG Focus Paper No. 2. Washington: Refugee Policy Group.

De Greiff, P. 2006. "Justice and Reparations", en P. de Greiff (ed.), The Handbook of Reparations: 451-477. Oxford: University Press.

Escobar, A. 1995. Encountering Development. The Making and Unmaking of the Third World. Princeton: Princeton University Press.

Falk, R. 2006. "Reparations, International Law, and Global Justice», en P. de Greiff (ed.), The Handbook of Reparations: 478-503. Oxford: University Press.

Galtung, J. 1969. "Violence, Peace, and Peace Research". Journal of Peace Research 6: 167-191.

García, E. 2011. Ondas de paz. El activismo mediatico de las mujeres periodistas contra la violencia sexual en el Congo contemporáneo (tesis doctoral). Bilbao: Universidad de Deusto.

Giddens, A. 2011 [1990]. Consecuencias de la modernidad. Madrid: Alianza

Grupo de Memoria Histórica de la Comisión Nacional de Reparación y Reconciliación (GMH). 2009. La masacre del salado: esa guerra no era nuestra. Bogotá: Taurus-Ediciones Semana.

Jimenez, C. 2010. "El campo psicosocial: conceptos e implicaciones”, en C. Díaz (ed.), Tareas pendientes. Propuestas para la formulación de políticas públicas de reparación en Colombia: 97-192. Bogotá: ICTJ. 
Jiménez, S. 2008. "Los discursos de transición y los sistemas de atención a víctimas como dispositivos de gestión del conflicto armado en Colombia", en S. Jimenez (Coord.), Desplazados, víctimas en permanente transición. Repensar la relación conflicto- postconflicto en Colombia como reconstrucción ética y política de la sociedad: 59-110. Bogotá: Ántropos.

Lyotard, J. F. 1983. Le Différend. París: Minuit.

Malkki, L. 1997. "Speechless Emissaries: Refugees, Humanitarianism, and Dehistoricization", en K. F. Olwig y K. Hastrup (eds.), Siting Culture. The Shifting Anthropological Object: 223-254. Londres: Routledge.

Mate, M. R. 2011. Tratado de la injusticia. Barcelona: Anthropos.

McLagan, M. 2006. "Introduction: Making Human Rights Claims Public". American Anthropologist 108(1): 191-195.

Mejía Vallejo, M. 1964. El Día señalado. Barcelona: Ediciones Destino.

Moyo, D. 2009. Dead Aid: Why Aid Is Not Working and How There is Another Way for Africa. Nueva York: Farrar, Straus \& Giroux.

O'Donnell, G. 2004. "Why the Rule of Law Matters". Journal of Democracy 15(4): 32-46.

Olivera, M. 2001. "Acteal: Effects of the Low Intensity War", en A. Hernández (ed.), The Other Word: Women and Violence in Chiapas before and after Acteal. Copenhage: International Work Group For Indigenous Affairs (IWGIA).

Todorov, T. 2002. Memoria del mal, tentación del bien. Indagación sobre el siglo XX. Barcelona: Península.

Todorov, T. 2008 [1995]. Los abusos de la memoria. Barcelona: Paidós.

Uprimny, R. 2013 (25 de julio). "Lo único reducible es el castigo y no la investigación". Revista Semana [en línea], disponible en: http://www.semana.com/nacion/articulo/lo-unico-reducible-castigo-noinvestigacion-rodrigo-uprimny/352007-3, [consultado el 03/03/2015].

Uprimny, R. y M. P. Saffon. 2009. "Reparaciones transformadoras, justicia distributiva y profundización democrática", en C. Diaz et al. (eds.), Reparar en Colombia: los dilemas en contextos de conflicto, pobreza y exclusion: 31-70. Bogotá: ICTJ \& DeJuSticia.

Velasco, H., A. Díaz, F. Cruces, R. Fernández, C. Jiménez y R. Sánchez. 2006. La sonrisa de la institución. Confianza y riesgo en sistemas expertos. Madrid: Editorial Ramón Areces.

Fecha de recepción: 14 de enero de 2015

Fecha de aceptación: 23 de febrero de 2015 